\title{
Biochemical Studies on Pomegranate
}

Nadia Y. A Attia. ${ }^{1}$; Ibrahim M. Abd EI - Aleem ${ }^{1}$; Kareem M.K. El Tobgy ${ }^{2}$ and Hala F. Mohamed ${ }^{2}$

1: Department of Biochemistry, Faculty of Agriculture, Moshtohor, Banha University.

2: Department of Medicinal and Aromatic Plants Research, Horticulture Research Institute, Agriculture

Research Center.

Abstract
Water, methanol and ethanol were used to extract total phenols, total tannins, anthocyanin, flavonoids and antioxidants activity from pomegranate peels (Punica granatum L) by using different methods. The obtained extracts and juice were used to study their antimicrobial effects against some Gram positive bacteria ( Staphylococcus aureus, Listeria monocytogenese, Bacillus megaterium and Bacillus cereus), some Gram negative bacteria ( Escherichia coli, Klebsiella pneumonia and Salmonella typi) and some fungi (Aspergillus niger and Candida albicans). Also, pomegranate juice and peel water extract were used to study their biological effects against diabetic and hypercholesterolemia in Wister rats. Water extract at $50^{\circ} \mathrm{C}$ for 20 min showed the highest capacity for extracting total phenols, total tannins, anthocyanin and total flavonoids compounds from dried pomegranate peels. Methanol extract at $50^{\circ} \mathrm{C}$ for 20 min recorded the highest antioxidant activity. All extracts recorded good inhibition for all the tested microorganisms. Administration of pomegranate juice and peel water extract induced significant decrement in blood serum glucose, triglycerides, total cholesterol, low density lipoprotein (LDL), urea, uric acid and creatinine in diabetic and hypercholesterolemia rats while, high density lipoprotein (HDL) elevated. Hematological parameters showed significant increment in white blood cells (WBC) in the diabetic group and in hypercholesterolemia group administrated with pomegranate juice red blood cells (RBC) and WBC showed significant increment.

Key words: pomegranate - antioxidant - antibacterial - lipid profile - liver functions

\section{Introduction}

The extraction of active compounds from plant materials is the first step in the utilization of phytochemicals in the preparation of dietary supplements, food ingredients and pharmaceuticals industries (Jin and Russell, 2010). It is generally known that the yield of chemical extraction depends on efficient methods for extraction, type of solvents with varying polarities, extraction time and temperature, as well as on the chemical composition and physical characteristics of the samples. Some previous researchers had reported that higher extraction yields of phenolic compounds were obtained with increasing solvent polarity (Moure $\boldsymbol{e t}$ al., 2000 and Cheung et al., 2000). Also, Wissam et al. (2012) studied the effective extraction of polyphenols and proanthocyanidins from pomegranate peel. They found that the recovery of polyphenols and proanthocyanidins were the highest at $50{ }^{\circ} \mathrm{C}$ for $20 \mathrm{~min}$. Water gave the highest extract yield of polyphenols and proanthocyanidins $(17.78 \%$ and $1.22 \%$ ). Also, they revealed that two sequential water extractions has the economic and safety merits, and can be used as an environmentally friendly method for producing antioxidants from the pomegranate peel.

Madrigal-Carballo et al. (2009) mentioned that tannins were the major phenolics in pomegranate peels, which were more readily dissolved in $50 \%$ methanol. A mixture of methanol, ethanol, acetone and water was found to be a better extractant of active phenolics from pomegranate. Also, Tm et al.
(2010) stated that distilled water at $60^{\circ} \mathrm{C}$ extraction conditions was the best for extracting anthocyanin.

Wang et al. (2011) extracted phenols from pomegranate peels by different solvent and temperature conditions. They found the methanol and water gave the highest extract yield of total phenols followed by water and ethanol. Also, they revealed that water extraction, which has the economic and safety merits, can be used as an environmentally friendly method for producing antioxidants from the pomegranate peel. Hadrich et al. (2014) reported that the methanol and ethanol extracts of pomegranate peels showed the most potent antioxidant activity followed by water and acetone extracts.

Al-Zoreky (2009) reported that the methanolic extract of pomegranate fruit induced antibacterial activity against Listeria monocytogenes, S. aureus, Escherichia coli and Yersinia enterocolitica, Candida utilis, Saccharomyces cerevisiae and Aspergillus niger. Shaokat et al. (2007) reported that there was little difference between the activities of alcoholic extract and aqueous extract of pomegranate airl against seven bacteria (Bacillus megaterium DSM 32, Pseudomonas aeruginosa DSM 9027, Staphylococcus aureus Cowan 1, orynebacterium xerosis UC 9165, Escherichia coli DM, Enterococcus faecalis $\mathrm{A} 10$ and Micrococcus luteus LA 2971), and three fungi (Kluvyeromyces marxianus A230, Rhodotorula rubra MC12 and Candida albicans ATCC 1023). Also, they observed that the pomegranate aril extracts had antimicrobial 
effects on all microorganisms, giving inhibition zones ranging in size from 13 to $26 \mathrm{~mm}$. Fawole $\boldsymbol{e t}$ al. (2013) studied the antibacterial activities of methanol and aqueous peel extracts of pomegranate against Gram-positive (Bacillus subtilis and Staphylococcus aureus) and Gram-negative bacteria (Escherichia coli and Klebsiella pneumonia). They indicated that the methanolic peel extracts showed strong broad-spectrum activity against Gram-positive and Gram-negative bacteria. None of the aqueous extracts exhibited good antibacterial activity at the highest screening concentration (> $12.5 \mathrm{mg} / \mathrm{ml}$ ). Hajoori et al. (2014) reported that Punica granatum peel water, ethanol, methanol, acetic acid and petroleum ether extracts had highly significant antimicrobial activity against four gram positive bacteria (Bacillus subtilis, Bacillus cereus, Staphylococcus aureus, Bacillus megaterium) and six strains of Gram negative bacteria (Escherichia coli, Salmonella typhi, Salmonella paratyphi A, Salmonella paratyphi $B$, Proteus vulgaris and Pseudomonas aeruginosa). Aqueous, ethanol and methanol extracts were found to be more active towards the microorganisms tested than acetic acid and petroleum ether extracts. Salmonella typhi and Proteus vulgaris were reported to have significant susceptibility against most of the extracts. Phytochemical analysis of $P$. granatum peel showed the presence of alkaloids, flavanoids, steroids, tannin, glycosides and terpenoids.

Bagri et al. (2009) found that the administration of pomegranate aqueous extract at doses of $250 \mathrm{mg} / \mathrm{kg}$ and $500 \mathrm{mg} / \mathrm{kg}$ for 21 days caused significant reduction in fasting blood glucose, cholesterol, triglycerides and LDL cholesterol in compression with diabetic group induced by sterptozotocin. Radhika et al. (2011) reported that Punica granatum had antidiabetic and hypoglycemic activity of rats treated with alloxan. Administration of crude powder Punica granatum reduced the concentration of glucose, triglycerides, cholesterol, LDL cholesterol, vLDL cholesterol and raised the level of HDL cholesterol of both normal group and diabetic treated group. Osman et al. (2012) concluded that diabetic rats treated with pomegranate peel and juice showed decrement in glucose, alpha amylase, triglycerides, total cholesterol, LDL cholesterol AST and ALT levels. While, HDL cholesterol and insulin level elevated. Bhandary $\boldsymbol{e t}$ al. (2013) stated that orally administration of ethanolic extracts of Punica granatum whole fruit and seeds ( $2000 \mathrm{mg} / \mathrm{kg}$ body weight) in Swiss albino rats showed that the total cholesterol, LDL and HDL levels recorded moderate non-significant increment while, triglyceride level recorded moderate decrement comparing with control. Total Protein and bilirubin, albumin and serum biomarkers of liver (ALT and AST), kidney (creatnine, uric acid and urea), hematological parameters ((RBC, WBC, Hb, and Platelet Count) did not record any significant alteration.

The aim of this investigation is to study the best method for extracting the antioxidants of pomegranate peel; evaluate pomegranate juice and peel extracts as antimicrobial effects and evaluate pomegranate juice and peel water extract as biological effects on diabetic and hypercholesterolemia rats.

\section{Plant Material}

Pomegranate was obtained from Horticulture Research Institute, Agriculture Research Center, Giza, Egypt (August 2013). Pomegranate fruit skins were cleaned, dried and ground to fine powders.

\section{Proximate analyses}

Moisture, ash, crude protein, crude fiber and total lipids contents were determined in pomegranate juice and peel according to A.O.A.C. (2005). Total hydrolysable carbohydrate was determined according to Dubois et al. (1956).

\section{Extraction methods}

Water, methanol and ethanol were used at $25^{\circ} \mathrm{C}$ for $24 \mathrm{~h}$, at $50^{\circ} \mathrm{C}$ for $20 \mathrm{~min}$ and by using Soxhelt apparatus in addition, boiling water for 5, 10, $20 \mathrm{~min}$ were used to identify the most suitable solvent for the extraction of total polyphenols, total tannins, anthocyanin, flavonoids and antioxidant. All extracts were then passed through filter paper and dried in oven at $50^{\circ} \mathrm{C}$.

\section{Chemical composition}

Total polyphenols content was estimated by the Folin-Ciocalteu method reported by Elfalleh $\boldsymbol{e t}$ al. (2009). Hydrolysable tannins content was determined by the method of Çam and Hişil (2010). Total anthocyanin content was determined according to Elfalleh et al. (2011) and Çam et al. (2009). The amount of total flavonoids in the extracts was measured spectrophotometrically by the method of Djeridane et al. (2006). The scavenging activity on DPPH radical of different extracts was determined according to the method reported by Okonogi $\boldsymbol{e t}$ al. (2007).

\section{Mic robial studies}

\section{Bacterial and fungal isolates}

Clinical isolates of $E$.coli NRRL B/210, Staph. aeureus NRRL B/3 B , Bacillus cereus NRRL B / G 43 , Bacillus megtarin NRRL B/1366, Listeria monocytogenase serotype NRRL Y/477, Klabsila pneumonia ATTCC700603 , Candida albicans NRRL Y/477, and Aspergillus niger NRRL/3 and Salmonella typhi ATTC5647006. were obtained from Department of chemistry of Natural and Microbial product, National Research Center, and were kept in the laboratory in the frozen state until used. 
Antimicrobial activity

Pomegranate juice and peel extracts were sterilized by using finally filter sterilization $0.2 \mu \mathrm{m}$ filter (Millipore) and stored in sterile vials. The antimicrobial effect of the pomegranate juice and peel extracts were evaluated using disk inhibition zone by the method described by Orak et al. (2011).

\section{Biological evaluation of water extract and juice.}

\section{a. Experimental animals.}

A total of 45 of adult's male albino rats (Wister Strain) weighed each of them $200 \mathrm{~g}$

approximately were obtained from Organization of Biological Products and Vaccines from Helwan breeding farm, Cairo, Egypt. The rats were housed in stain lasted cages with wire mesh bottoms in a room temperature maintained at $25{ }^{\circ} \mathrm{C} \pm 2{ }^{\circ} \mathrm{C}$. Rats were kept under normal healthy conditions for one week and fed on basal diet. The diet contained Casein $10 \%$, Corn oil 10\%, Salt mixture $4 \%$, Vitamin mixture 1\%, Cellulose 5\% and starch 70\% (Reeves $\boldsymbol{e t}$ al 1993).

Dosage and administration of decoction: The decoction was administered at a dosage of 3 $\mathrm{ml} / \mathrm{kg} /$ day of pomegranate juice and $200 \mathrm{mg} / \mathrm{kg} /$ day of pomegranate peel water extract (Abdel Moneim et al 2011), using a Sondi needle by gastric gavage method ( Iddamaldeniya et al 2006). After that the rats were divided into three main groups 15 rats each. The first main group (control) was divided into three subgroups (5 rats each) the first (control) was fed on basil diet for another 6 weeks. The second group was fed on basil diet and administered of pomegranate juice. The third was fed on basil diet and administered of pomegranate peel water extract.

The second main group was the diabetic group. The rats were injected with a single dose of alloxan solution $150 \mathrm{mg} \backslash \mathrm{kg}$ body weight (Buko et al 1996). After 24 hours of alloxan injection, diabetes was confirmed (glucose blood was higher than 180 $\mathrm{mg} / \mathrm{dl}$ ). Rats were left for one week for stabilize diabetes, and then rats were divided into three subgroups. The first (control diabetic) was fed on basil diet for another 6 weeks. The second was fed on basil diet and administered of pomegranate juice. The third was fed on basil diet and administered of pomegranate peel water extract.

The third main group was hypercholesterolemia group. The rats were fed on high fat diet similar to the control diet but differed in more fat content which was $10 \%$ sheep fat, $2 \%$ cholesterol and $0.25 \%$ bile salts and starch $57.75 \%$ for 2 weeks (AbdelRahim et al 2013), then was divided into three subgroups. The first (hypercholesterolemia control) was fed with basil diet for another 6 weeks. The second was fed on basil diet and administered of pomegranate juice. The third was fed on basil diet and administered of pomegranate peel water extract.

\section{Blood sample}

At the end of experiment blood was collected in tubes from retro-orbital vein in two separated tubes, one tube with EDTA (ethylene diamine tetra acetic acid) for the determination of hematological parameter and the other was centrifuged at $3000 \mathrm{rpm}$ for $20 \mathrm{~min}$, for serum preparation.

\section{Serum analysis}

Serum parameters were determined by enzymatic colorimetric methods, glucose was determined according to the procedure of Trinder (1969). Serum triglyceride and total cholesterol were determined according to the methods of Fossati and Prencipe (1982) and Allain et al. (1974). Low density lipoprotein (LDL-cholesterol) and high density lipoprotein (HDL- cholesterol) were determined according to the method of Tietz (1976 a). Serum total bilirubin, total protein and albumin were determined according to the method of Walters and Gerarde (1970), Vassault et al. (1986) and Young et al. (1975). Alkaline phosphatases (ALP) was determined according to the methods of Young et al. (1972). Serum aspartate transferease (AST) and alanine transferease (ALT) activities were measured colorimetrically according to the method of Tietz (1976 b). Serum urea, uric acid and creatinine were determined according to Tietz (1990), Vassault et al. (1986) and Tietz (1986).

\section{Heamatology}

The red blood cells (RBC), white blood cells (WBC) counts, and the hemoglobin $(\mathrm{Hb})$ were determined in Mindray 2800 hematology analyzer.

\section{Statistical analysis.}

Statistical analysis was done by Duncan's Methods (SAS, 1996).

\section{Results and discussion}

\section{Chemical composition}

Data concerning pomegranate peel and juice chemical composition are shown in Table (1).

Table 1. Chemical composition of pomegranate peel and juice.

\begin{tabular}{lll}
\hline Constituents & $\begin{array}{l}\text { Pomegranate } \\
\text { peel based on } \\
\text { dry weight } \\
(\%)\end{array}$ & $\begin{array}{l}\text { Pomegranate } \\
\text { juice } \\
\text { based on } \\
\text { fresh weight } \\
(\%)\end{array}$ \\
\hline Moisture & 5.03 & 86.60 \\
Crude fiber & 10.40 & ----- \\
Ash & 2.15 & 0.42 \\
Crude protein & 2.59 & 0.13 \\
Total lipid & 1.80 & 0.06 \\
Total carbohydrate & 79.08 & 13.35 \\
\hline
\end{tabular}

Pomegranate peels (dry weight) consist of $5.03 \%$ moisture, $10.40 \%$ crude fiber, $2.15 \%$ ash, 
$2.59 \%$ crude protein, $1.80 \%$ total lipid, $79.08 \%$ total carbohydrates.

Data concerning crude fiber and total carbohydrate are in agreement with those reported by Rowayshed et al. (2013). Data of pomegranate juice show that the juice consisted of 86.6, 0.42, 0.13 , 0.06 and $13.35 \%$ moisture, ash, crude protein, total lipid and total carbohydrates respectively. Similar results were obtained by Ramadan et al. (2010) for moisture, ash, protein, and carbohydrate.

\section{Extraction.}

Data in Table (2) show the effect of extraction methods on the total phenols, total tannins, anthocyanin, total flavonoids and antioxidants activity.

Table 2 Effect of different extraction methods on total phenols, total tannins, anthocyanin, total flavonoids and antioxidants activity.

\begin{tabular}{|c|c|c|c|c|c|}
\hline Extraction methods & $\begin{array}{l}\text { Total phenols } \\
\mathrm{g} / 100 \mathrm{~g}\end{array}$ & $\begin{array}{l}\text { Total tannins } \\
\mathrm{g} / 100 \mathrm{~g}\end{array}$ & $\begin{array}{l}\text { Anthocyanin } \\
\mathrm{mg} / 100 \mathrm{~g}\end{array}$ & $\begin{array}{l}\text { Total } \\
\text { flavonoids } \\
\mathrm{mg} / 100 \mathrm{~g}\end{array}$ & $\begin{array}{l}\text { Antioxidants } \\
\text { activity } \%\end{array}$ \\
\hline $\begin{array}{l}\text { Water extract at } 25^{\circ} \mathrm{C} \\
\text { for } 24 \mathrm{~h}\end{array}$ & $4.28 c \pm 0.19$ & $1.36 \mathrm{a} \pm 0.15$ & $73.60 b \pm 2.69$ & $39.15 b \pm 1.41$ & $\begin{array}{l}78.41 \mathrm{c} \\
1.55\end{array}$ \\
\hline $\begin{array}{l}\text { Methanol extract at } \\
25^{\circ} \mathrm{C} \text { for } 24 \mathrm{~h}\end{array}$ & $4.60 c \pm 0.29$ & $1.13 \mathrm{~b} \pm 0.06$ & $49.49 \mathrm{c} \pm 1.68$ & $\begin{array}{ll}35.75 b c \quad \pm \\
2.26\end{array}$ & $\begin{array}{l}87.88 \mathrm{ab} \\
2.5\end{array}$ \\
\hline $\begin{array}{l}\text { Ethanol extract at } 25^{\circ} \mathrm{C} \\
\text { for } 24 \mathrm{~h}\end{array}$ & $3.38 \mathrm{~d} \pm 0.28$ & $0.95 c \pm 0.07$ & $41.94 \mathrm{e} \pm 1.6$ & $31.04 \mathrm{~d} \pm 1.01$ & $\begin{array}{l}87.21 \mathrm{~b} \\
1.37\end{array}$ \\
\hline $\begin{array}{l}\text { Water extract at } 50^{\circ} \mathrm{C} \\
\text { for } 20 \mathrm{~min}\end{array}$ & $6.72 a \pm 0.28$ & $1.37 \mathrm{a} \pm 0.12$ & $86.19 \mathrm{a} \pm 2.25$ & $\begin{array}{l}43.48 \mathrm{a} \\
3.72\end{array}$ & $\begin{array}{l}80.85 b \\
1.49\end{array}$ \\
\hline $\begin{array}{l}\text { Methanol extract at } \\
50^{\circ} \mathrm{C} \text { for } 20 \mathrm{~min}\end{array}$ & $5.85 b \pm 0.21$ & $1.29 \mathrm{a} \pm 0.08$ & $48.30 \mathrm{~d} \pm 1.57$ & $\begin{array}{l}38.51 \mathrm{bc} \quad \pm \\
2.50\end{array}$ & $\begin{array}{l}90.58 \mathrm{a} \\
2.86\end{array}$ \\
\hline $\begin{array}{l}\text { Ethanol extract at } 50^{\circ} \mathrm{C} \\
\text { for } 20 \mathrm{~min}\end{array}$ & $4.65 c \pm 0.18$ & $1.16 \mathrm{~b} \pm 0.12$ & $38.55 \mathrm{~g} \pm 1.47$ & $37.76 \mathrm{bc}$ & $\begin{array}{l}86.39 \mathrm{~b} \\
1.40\end{array}$ \\
\hline Boiling water for $5 \mathrm{~min}$ & $2.761 \mathrm{e} \pm 0.15$ & $0.74 \mathrm{~d} \pm 0.01$ & $40.57 \mathrm{f} \pm 1.71$ & $28.87 \mathrm{~d} \pm 0.54$ & $\begin{array}{l}74.90 \mathrm{~d} \\
1.42\end{array}$ \\
\hline Boiling water for10 min & $1.81 \mathrm{f} \pm 0.15$ & 0.68 de \pm 0.02 & $37.04 \mathrm{~h} \pm 1.75$ & $25.68 \mathrm{e} \pm 2.60$ & $\begin{array}{l}71.04 \mathrm{e} \\
2.03\end{array}$ \\
\hline Boiling water for $20 \mathrm{~min}$ & $1.23 g \pm 0.07$ & $0.53 f \pm 0.05$ & $32.30 \mathrm{i} \pm 1.24$ & $21.31 \mathrm{f} \pm 0.61$ & $\begin{array}{l}60.78 \mathrm{f} \\
1.39\end{array}$ \\
\hline Water Soxhlet extract & $1.02 \mathrm{~g} \pm 0.05$ & $0.41 \mathrm{~g} \pm 0.02$ & $14.75 \mathrm{k} \pm 1.02$ & $10.26 \mathrm{~h} \pm 0.31$ & $\begin{array}{l}55.62 \mathrm{~g} \\
1.20\end{array}$ \\
\hline $\begin{array}{l}\text { Methanol Soxhlet } \\
\text { extract }\end{array}$ & $1.43 g \pm 0.07$ & 0.61 ef \pm 0.03 & $15.63 \mathrm{j} \pm 0.91$ & $17.88 \mathrm{~g} \pm 0.68$ & $\begin{array}{l}72.41 \mathrm{de} \\
2.50\end{array}$ \\
\hline Ethanol Soxhlet extract & $1.17 \mathrm{~g} \pm 0.04$ & $0.58 \mathrm{f} \pm 0.02$ & $15.62 \mathrm{j} \pm 1.20$ & $11.88 \mathrm{~h} \pm 1.12$ & $\begin{array}{l}71.61 \mathrm{e} \pm 3.4 \\
0\end{array}$ \\
\hline
\end{tabular}

$\mathrm{a}, \mathrm{b}, \mathrm{c}, \ldots \ldots \mathrm{k}$ means within column with different letters differ significantly $(\mathrm{p} \leq 0.05)$ from each other means followed by the same letter don't differ at 0.05 probability level.

The obtained results indicate that water extract at $50^{\circ} \mathrm{C}$ for $20 \mathrm{~min}$ followed by methanol extract at $50^{\circ} \mathrm{C}$ for $20 \mathrm{~min}$ recorded the highest extraction of total polyphenols. Total tannins recorded the highest value in water extracts at $50^{\circ} \mathrm{C}$ for $20 \mathrm{~min}$ and at 25 ${ }^{\circ} \mathrm{C}$ for $24 \mathrm{~h}$ followed by methanol extract at $50^{\circ} \mathrm{C}$ for $20 \mathrm{~min}$. Water extract at $50{ }^{\circ} \mathrm{C}$ for $20 \mathrm{~min}$ and at 25 ${ }^{\circ} \mathrm{C}$ for $24 \mathrm{~h}$ showed the highest capacity for extracting anthocyanin. Total flavonoids recorded the highest value in water extracts at $50{ }^{\circ} \mathrm{C}$ for $20 \mathrm{~min}$ and at $25{ }^{\circ} \mathrm{C}$ for $24 \mathrm{~h}$ followed by methanol, ethanol extracts at $50{ }^{\circ} \mathrm{C}$ for $20 \mathrm{~min}$. Antioxidant showed the highest activity in methanol extract at $50{ }^{\circ} \mathrm{C}$ for 20 min and at $25^{\circ} \mathrm{C}$ for $24 \mathrm{~h}$ followed by ethanol extract at $25^{\circ} \mathrm{C}$ for $24 \mathrm{~h}$.

Increasing water boiling time caused significant decrement in total polyphenols, total tannins, anthocyanin, total flavonoids and antioxidant activity. Soxhlet extracts showed the lowest extraction efficiency.

It could be conculated that water at $50^{\circ} \mathrm{C}$ for 20 min was the best solvent for extracting total phenols, total tannin, total anthocyanin and total flavonoids.

The obtained results are in agreement with those obtained by Noda et al. (2002), Hohnov et al. (2008), Madrigal-Carballo et al. (2009), Wang et al. (2011) and Orak et al. (2012). Al-Rawahi et al. (2013) reported that the polyphenols of the pomegranate are relatively polar compounds, where hydrogen bonds, dipole-dipole, and electrostatic interactions may contribute to their strong solubility in polar solvents, water as the highest polar solvent, as it extracted the highest phenolic compounds followed by methanol and ethanol. 
Antimicrobial effects:-

Antimicrobial effects of pomegranate peel extracts and juice:

Effect of pomegranate peel extracts and juice on some Gram positive bacteria:

Table (3) show the antimicrobial effect of various pomegranate peel extracts and juice against some Gram positive bacteria; Staphylococcus aureus, Listeria monocytogenese, Bacillus megaterium and Bacillus cereus.

\section{Staphylococcus aureus}

Results show that ethanol extract at $50{ }^{\circ} \mathrm{C}$ for 20 min, boiling water extract for $5 \mathrm{~min}$ and methanol extract at $50{ }^{\circ} \mathrm{C}$ for $20 \mathrm{~min}$ had the highest inhibition activity. Pomegranate juice had no antimicrobial activity.

\section{Listeria monocytogenese}

Methanol extract at $50^{\circ} \mathrm{C}$ for 20 min showed the highest inhibition zone followed by methanol Soxhelt extract. Pomegranate juice had no antimicrobial activity.

\section{Bacillus megaterium:}

Methanol extracts at $50^{\circ} \mathrm{C}$ for $20 \mathrm{~min}$ and at $25^{\circ} \mathrm{C}$ for $24 \mathrm{~h}$ had the highest inhibition zone 24.33 and $23.17 \mathrm{~mm}$. Pomegranate juice recorded $17.17 \mathrm{~mm}$ inhibition zone.

\section{Bacillus cereus}

Methanol and ethanol extracts at $50^{\circ} \mathrm{C}$ for 20 min and methanol extract at $25{ }^{\circ} \mathrm{C}$ for $24 \mathrm{~h}$ showed the highest antimicrobial effect. Water extract at $50^{\circ} \mathrm{C}$ for $20 \mathrm{~min}$ showed $24.50 \mathrm{~mm}$ inhibition zone. Pomegranate juice recorded $13.67 \mathrm{~mm}$ inhibition zone.

These results are in agreement with those reported by Khan and Hanee (2011), Dahham et al. (2010), Orak et al. (2011) and Hajoori et al. (2014).

Effect of pomegranate peel extracts and juice on some Gram negative bacteria

Data present in Table (4) show the effect of various pomegranate peel extracts and juice against some Gram negative bacteria (Escherichia coli, Klebsiella pneumonia and Salmonella typi).

\section{Escherichia coli}

Methanol extract at $50^{\circ} \mathrm{C}$ for $20 \mathrm{~min}$ and boiling water extract for $5 \mathrm{~min}$ recorded the highest inhibition zone ( 21.50 and $20.83 \mathrm{~mm}$ ). Pomegranate juice recorded $13.83 \mathrm{~mm}$ inhibition zone.

\section{Klebsiella pneumonia}

Methanol and ethanol extracts at $50^{\circ} \mathrm{C}$ for 20 min, recorded the highest inhibition zone ( 32.00 and
$31.33 \mathrm{~mm}$ ). Pomegranate juice antimicrobial activity was $26.17 \mathrm{~mm}$.

Salmonella typhi :

Methanol extracts at $50^{\circ} \mathrm{C}$ for $20 \mathrm{~min}$ and at $25^{\circ} \mathrm{C}$ for $24 \mathrm{~h}$ showed the highest inhibition zones and the recorded means were 22.67 and $21.00 \mathrm{~mm}$. Pomegranate juice antimicrobial activity recorded $13.83 \mathrm{~mm}$.

The obtained results are in agreement with those reported by Perez and Anesini (1994), AlZoreky (2009), Orak et al. (2011) and Hajoori et al (2014).

Mean time, AlFadel et al (2014) reported that pomegranate ethanol extract showed antimicrobial effect while, pomegranate water extract had no antimicrobial activity

\section{Effect of pomegranate peel extracts and juice on} some fungi

Data in Table (5) present the effect of pomegranate peel extracts and juice against some fungi (Aspergillus niger and Candida albicans). Aspergillus niger :

Methanol extracts at $25^{\circ} \mathrm{C}$ for $24 \mathrm{hr}$ and at $50^{\circ}$ $\mathrm{C}$ for $20 \mathrm{~min}$ had the highest inhibition zones followed by ethanol extract at $50 \mathrm{C}^{\circ}$ for $20 \mathrm{~min}$ Pomegranate juice recorded $12.83 \mathrm{~mm}$.

Candida albicans :

Methanol extract at $50^{\circ} \mathrm{C}$ for $20 \mathrm{~min}$ had the highest inhibition zone followed by methanol, ethanol extracts at $25^{\circ} \mathrm{C}$ for $24 \mathrm{hr}$. Pomegranate juice antimicrobial activity recorded $17.5 \mathrm{~mm}$ inhibition zone.

The obtained results are in agreement with those reported by Al Zoreky (2009) and Dahham et al (2010).

\section{Biological effects:-}

Data concerning the effect of pomegranate juice and peel water extract on blood serum glucose and lipid profile are shown in Table (6).

In diabetic and hypercholesterolemia groups there was significant increment in glucose level comparing with control group. Administration with pomegranate juice and peel water extract caused significant decrement in serum glucose levels in diabetic and hypercholesterolemia groups.

The obtained results are in agreement with those obtained by Radhika et al. (2011) and Osman et al. (2012). 
Table 3. Effect of pomegranate peel extracts and juice on some Gram positive bacteria.

\begin{tabular}{|c|c|c|c|c|c|c|c|c|c|c|c|c|}
\hline \multirow[t]{2}{*}{ Treatments } & \multicolumn{3}{|c|}{ Staph. Aureus } & \multirow{2}{*}{\multicolumn{3}{|c|}{$\begin{array}{l}\text { Listeria monocytogenese } \\
\text { Inhibition zone }(\mathrm{mm})\end{array}$}} & \multicolumn{3}{|c|}{ Bacillus megaterium } & \multicolumn{3}{|c|}{ Bacillus cereus } \\
\hline & & & & & & & & & & & & \\
\hline & $20 \mu$ & $40 \mu$ & Mean & $20 \mu$ & $40 \mu$ & mean & $20 \mu$ & $40 \mu$ & mean & $20 \mu$ & $40 \mu$ & Mean \\
\hline $\begin{array}{l}\text { Water extract at } \\
25^{\circ} \mathrm{C} \text { for } 24 \mathrm{~h}\end{array}$ & $\begin{array}{l}12.67 \mathrm{hi} \\
\pm 0.58\end{array}$ & $\begin{array}{c}20.00 \mathrm{bd} \\
\pm 2.89\end{array}$ & $16.33 \mathrm{DE}$ & $\begin{array}{c}16.33 \mathrm{kl} \\
\pm 1.8\end{array}$ & $\begin{array}{c}20.67 \mathrm{dh} \\
\pm 1.80\end{array}$ & $18.50 \mathrm{E}$ & $\begin{array}{l}14.33 \mathrm{~h} \\
\pm 1.53\end{array}$ & $\begin{array}{l}24.0 \mathrm{~b} \\
\pm 1.00\end{array}$ & $19.17 \mathrm{C}$ & $\begin{array}{l}18.33 \mathrm{ef} \\
\pm 3.61\end{array}$ & $\begin{array}{l}30.00 \mathrm{a} \\
\pm 4.00\end{array}$ & $24.17 \mathrm{BC}$ \\
\hline $\begin{array}{l}\text { Ethanol extract at } \\
25^{\circ} \mathrm{C} \text { for } 24 \mathrm{~h}\end{array}$ & $\begin{array}{c}14.67 \mathrm{fh} \\
\pm 2.31\end{array}$ & $\begin{array}{l}21.33 \mathrm{bc} \\
\pm 2.08\end{array}$ & $18.00 \mathrm{CD}$ & $\begin{array}{l}17.32 \mathrm{ik} \\
\pm 2.31\end{array}$ & $\begin{array}{c}22.33 \mathrm{af} \\
\pm 4.18\end{array}$ & $19.80 \mathrm{CE}$ & $\begin{array}{l}16.0 \mathrm{fi} \\
\pm 1.9\end{array}$ & $\begin{array}{l}27.0 \mathrm{a} \\
\pm 3.9\end{array}$ & $21.50 \mathrm{~B}$ & $\begin{array}{l}19.0 \mathrm{df} \\
\pm 1.15\end{array}$ & $\begin{array}{l}25.67 \mathrm{bc} \\
\pm 0.58\end{array}$ & $22.33 \mathrm{C}$ \\
\hline $\begin{array}{l}\text { Methanol extract at } \\
25^{\circ} \mathrm{C} \text { for } 24 \mathrm{~h}\end{array}$ & $\begin{array}{l}\text { 12.0hi } \\
\pm 1.15\end{array}$ & $\begin{array}{l}19.00 \mathrm{~cd} \\
\pm 2.5\end{array}$ & $15.50 \mathrm{EF}$ & $\begin{array}{l}21.00 \mathrm{cg} \\
\pm 3.58\end{array}$ & $\begin{array}{c}22.00 \mathrm{bf} \\
\pm 3.70\end{array}$ & $21.50 \mathrm{BC}$ & $\begin{array}{l}20.33 \mathrm{~cd} \\
\pm 2.00\end{array}$ & $\begin{array}{l}26.0 \mathrm{ab} \\
\pm 2.58\end{array}$ & $23.17 \mathrm{AB}$ & $\begin{array}{l}22.0 \mathrm{~d} \\
\pm \quad 2.8\end{array}$ & $\begin{array}{l}28.67 \mathrm{ab} \\
\pm 1.15\end{array}$ & $25.30 \mathrm{~B}$ \\
\hline $\begin{array}{l}\text { Water extract at } \\
50^{\circ} \mathrm{C} \text { for } 20 \mathrm{~min}\end{array}$ & $\begin{array}{c}14.33 \mathrm{gi} \\
\pm 1.5\end{array}$ & $\begin{array}{c}22.33 \mathrm{ab} \\
\pm 1.15\end{array}$ & $18.33 \mathrm{C}$ & $\begin{array}{l}19.67 \mathrm{fj} \\
\pm 2.08\end{array}$ & $\begin{array}{c}23.00 \mathrm{ad} \\
\pm 2.00\end{array}$ & 21.33BD & $\begin{array}{l}16.33 \mathrm{ei} \\
\pm 3.46\end{array}$ & $\begin{array}{c}26.67 \mathrm{ab} \\
\pm 1.15\end{array}$ & $21.50 \mathrm{~B}$ & $\begin{array}{l}21.0 \mathrm{de} \\
\pm 2.52\end{array}$ & $\begin{array}{l}28.00 \mathrm{ac} \\
\pm 1.15\end{array}$ & $24.50 \mathrm{BC}$ \\
\hline $\begin{array}{l}\text { Ethanol extract at } \\
50^{\circ} \mathrm{C} \text { for } 20 \mathrm{~min}\end{array}$ & $\begin{array}{c}17.33 \mathrm{df} \\
\pm 1.15\end{array}$ & $\begin{array}{l}24.67 \mathrm{a} \\
\pm 2.31\end{array}$ & $21.00 \mathrm{~A}$ & $\begin{array}{l}18.67 \mathrm{jk} \\
\pm 2.31\end{array}$ & $\begin{array}{c}23.33 \mathrm{ad} \\
\pm 2.65\end{array}$ & $21.00 \mathrm{BD}$ & $\begin{array}{c}16.67 \mathrm{dg} \\
\pm 4.00\end{array}$ & $\begin{array}{c}26.00 \mathrm{ab} \\
\pm 4.58\end{array}$ & 21.83B & $\begin{array}{l}21.00 \mathrm{de} \\
\pm 4.81\end{array}$ & $\begin{array}{l}30.00 \mathrm{a} \\
\pm 2.08\end{array}$ & $25.50 \mathrm{~B}$ \\
\hline $\begin{array}{l}\text { Methanol extract at } \\
50^{\circ} \mathrm{C} \text { for } 20 \mathrm{~min}\end{array}$ & $\begin{array}{l}13.67 \mathrm{gi} \\
\pm 2.7\end{array}$ & $\begin{array}{l}24.33 \mathrm{a} \\
\pm 2.52\end{array}$ & $19.02 \mathrm{BC}$ & $\begin{array}{c}23.67 \mathrm{ac} \\
\pm 4.73\end{array}$ & $\begin{array}{l}25.00 \mathrm{a} \\
\pm 5.41\end{array}$ & $24.33 \mathrm{~A}$ & $\begin{array}{l}20.67 \mathrm{c} \\
\pm 1.58\end{array}$ & $\begin{array}{l}28.00 \mathrm{a} \\
\pm 1.84\end{array}$ & $24.33 \mathrm{~A}$ & $\begin{array}{l}25.33 \mathrm{c} \\
\pm 2.00\end{array}$ & $\begin{array}{l}30.33 \mathrm{a} \\
\pm 4.00\end{array}$ & $27.83 \mathrm{~A}$ \\
\hline $\begin{array}{l}\text { Boiling water for } 5 \\
\text { min }\end{array}$ & $\begin{array}{c}19.00 \mathrm{~cd} \\
\pm 1.00\end{array}$ & $\begin{array}{c}22.67 \mathrm{ab} \\
\pm 3.6\end{array}$ & $20.83 \mathrm{AB}$ & $\begin{array}{c}18.00 \mathrm{hk} \\
\pm 1.98\end{array}$ & $\begin{array}{c}22.67 \mathrm{ae} \\
\pm 1.53\end{array}$ & $20.33 \mathrm{BE}$ & $\begin{array}{c}17.69 \mathrm{dg} \\
\pm 1.50\end{array}$ & $\begin{array}{l}19.00 \mathrm{ce} \\
\pm 2.00\end{array}$ & 18.33CE & $\begin{array}{l}14.33 \mathrm{gi} \\
\pm 1.58\end{array}$ & $\begin{array}{l}16.33 \mathrm{fg} \\
\pm 2.52\end{array}$ & $15.33 \mathrm{D}$ \\
\hline $\begin{array}{l}\text { Boiling water } \\
\text { for10 min }\end{array}$ & $\begin{array}{l}14.00 \mathrm{gi} \\
\pm 1.50\end{array}$ & $\begin{array}{l}15.67 \mathrm{eg} \\
\pm 0.58\end{array}$ & $14.83 \mathrm{EF}$ & $\begin{array}{l}11.33 \mathrm{~m} \\
\pm 1.5\end{array}$ & $\begin{array}{l}17.33 \mathrm{ik} \\
\pm 1.73\end{array}$ & $14.33 \mathrm{~F}$ & $\begin{array}{l}15.00 \mathrm{gi} \\
\pm 2.00\end{array}$ & $\begin{array}{c}16.67 \mathrm{eh} \\
\pm 1.00\end{array}$ & $15.83 \mathrm{~F}$ & $\begin{array}{l}12.67 \mathrm{ij} \\
\pm 1.16\end{array}$ & $\begin{array}{l}15.00 \mathrm{gi} \\
\pm 1.53\end{array}$ & $13.33 \mathrm{DE}$ \\
\hline $\begin{array}{l}\text { Boiling water for } \\
20 \mathrm{~min}\end{array}$ & $\begin{array}{l}12.33 \mathrm{hi} \\
\pm 2.00\end{array}$ & $\begin{array}{l}15.67 \mathrm{eg} \\
\pm 2.08\end{array}$ & $14.00 \mathrm{~F}$ & $\begin{array}{l}11.33 \mathrm{~m} \\
\pm 1.00\end{array}$ & $\begin{array}{l}13.00 \mathrm{n} \\
\pm 2.90\end{array}$ & $12.17 \mathrm{G}$ & $\begin{array}{l}12.0 \mathrm{jk} \\
\pm 0.58\end{array}$ & $\begin{array}{l}15.00 \mathrm{gi} \\
\pm 2.08\end{array}$ & $13.50 \mathrm{G}$ & $\begin{array}{l}12.33 \mathrm{ij} \\
\pm 2.53\end{array}$ & $\begin{array}{l}15.00 \mathrm{gi} \\
\pm 1.53\end{array}$ & $13.67 \mathrm{DE}$ \\
\hline $\begin{array}{l}\text { Water Soxhlet } \\
\text { extract }\end{array}$ & $\begin{array}{l}11.67 \mathrm{i} \\
\pm 2.53\end{array}$ & $\begin{array}{l}17.33 \mathrm{df} \\
\pm 3.58\end{array}$ & $14.50 \mathrm{EF}$ & $\begin{array}{l}14.001 \mathrm{~m} \\
\pm 3.5\end{array}$ & $\begin{array}{l}17.00 \mathrm{jk} \\
\pm 4.60\end{array}$ & $15.50 \mathrm{~F}$ & $\begin{array}{l}11.67 \mathrm{k} \\
\pm 2.52\end{array}$ & $\begin{array}{c}13.67 \mathrm{ik} \\
\pm 1.53\end{array}$ & $12.67 \mathrm{G}$ & $\begin{array}{c}11.0 \mathrm{j} \\
\pm 1.73\end{array}$ & $\begin{array}{l}14.67 \mathrm{gi} \\
\pm 1.25\end{array}$ & $12.83 \mathrm{E}$ \\
\hline $\begin{array}{l}\text { Ethanol Soxhlet } \\
\text { extract }\end{array}$ & $\begin{array}{c}13.67 \mathrm{gi} \\
\pm 1.7\end{array}$ & $\begin{array}{c}17.67 \mathrm{de} \\
\pm 2.8\end{array}$ & $15.67 \mathrm{EF}$ & $\begin{array}{l}17.0 \mathrm{jk} \\
\pm 2.40\end{array}$ & $\begin{array}{c}21.67 \mathrm{bf} \\
\pm 1.79\end{array}$ & 19.33DE & $\begin{array}{l}15.33 \mathrm{fi} \\
\pm 1.37\end{array}$ & $\begin{array}{l}18.00 \mathrm{cf} \\
\pm 1.06\end{array}$ & $16.60 \mathrm{EF}$ & $\begin{array}{l}12.67 \mathrm{ij} \\
\pm 1.14\end{array}$ & $\begin{array}{l}16.00 \mathrm{fh} \\
\pm 0.33\end{array}$ & 14.33DE \\
\hline $\begin{array}{l}\text { Methanol Soxhlet } \\
\text { extract }\end{array}$ & $\begin{array}{l}17.33 \mathrm{df} \\
\pm 1.53\end{array}$ & $\begin{array}{l}19.00 \mathrm{~cd} \\
\pm 1.07\end{array}$ & 18.17CD & $\begin{array}{c}20.00 \mathrm{ei} \\
\pm 2.00\end{array}$ & $\begin{array}{l}24.33 \mathrm{ab} \\
\pm 1.98\end{array}$ & 22.17B & $\begin{array}{l}17.67 \mathrm{dg} \\
\pm 1.53\end{array}$ & $\begin{array}{c}19.67 \mathrm{~cd} \\
\pm 2.06\end{array}$ & $18.67 \mathrm{CD}$ & $\begin{array}{l}13.00 \mathrm{hj} \\
\pm 1.50\end{array}$ & $\begin{array}{l}16.00 \mathrm{fh} \\
\pm 1.00\end{array}$ & 14.50DE \\
\hline Pomegranate juice & $0.00 \mathrm{j}$ & $0.00 \mathrm{j}$ & $0.00 \mathrm{G}$ & $0.00 \mathrm{n}$ & $0.00 \mathrm{n}$ & $0.00 \mathrm{H}$ & $\begin{array}{l}14.67 \mathrm{hj} \\
\pm 2.65\end{array}$ & $\begin{array}{l}19.67 \mathrm{~cd} \\
\pm 3.15\end{array}$ & 17.17DF & $\begin{array}{l}12.67 \mathrm{ij} \\
\pm 1.48\end{array}$ & $\begin{array}{l}14.67 \mathrm{gi} \\
\pm 1.37\end{array}$ & $13.67 \mathrm{DE}$ \\
\hline Mean conc. & $13.28 \mathrm{~B}$ & $18.44 \mathrm{~A}$ & & $16.03 \mathrm{~B}$ & $19.41 \mathrm{~A}$ & & $16.1 \mathrm{~B} \backslash$ & $21.49 \mathrm{~A}$ & & $16.56 \mathrm{~B}$ & $21.56 \mathrm{~A}$ & \\
\hline
\end{tabular}


Table 4. ect of pomegranate peel extracts and juice on some Grame negative bacteria

$\begin{array}{lll}\text { Treatments } & \text { E. coli } & \text { Klebsiella pneumonia }\end{array}$

Salmonella typhi

inhibition zone (mm)

\begin{tabular}{|c|c|c|c|c|c|c|c|c|c|}
\hline & $20 \mu$ & $40 \mu$ & Mean & $20 \mu$ & $40 \mu$ & Mean & $20 \mu$ & $40 \mu$ & mean \\
\hline $\begin{array}{l}\text { Water extract at } 25^{\circ} \mathrm{C} \text { for } \\
24 \mathrm{~h}\end{array}$ & $\begin{array}{l}11.73 \mathrm{jk} \\
\pm 1.50\end{array}$ & $\begin{array}{l}22.67 \mathrm{~b} \\
\pm 2.54\end{array}$ & $17.20 \mathrm{D}$ & $\begin{array}{l}17.67 \ln \\
\pm 2.53\end{array}$ & $\begin{array}{c}20.67 \mathrm{hj} \\
\pm 2.51\end{array}$ & $19.17 \mathrm{~F}$ & $12.67 \mathrm{hi} \pm 1.8$ & $\begin{array}{l}18.33 \mathrm{~d} \\
\pm 2.89\end{array}$ & $15.50 \mathrm{FG}$ \\
\hline $\begin{array}{l}\text { Ethanol extract at } 25^{\circ} \mathrm{C} \text { for } \\
24 \mathrm{~h}\end{array}$ & $\begin{array}{c}12.67 \mathrm{ik} \\
\pm 1.50 \\
\end{array}$ & $\begin{array}{l}22.00 \mathrm{~b} \\
\pm 4.19 \\
\end{array}$ & $17.33 \mathrm{D}$ & $\begin{array}{c}18.33 \mathrm{jm} \\
\pm 1.50 \\
\end{array}$ & $\begin{array}{l}22.33 \mathrm{fh} \\
\pm 2.89 \\
\end{array}$ & $20.33 \mathrm{EF}$ & $\begin{array}{c}14.33 \mathrm{gh} \\
\pm 2.31\end{array}$ & $\begin{array}{l}22.67 \mathrm{bc} \\
\pm 2.08\end{array}$ & 18.50DE \\
\hline $\begin{array}{l}\text { Methanol extract at } 25^{\circ} \mathrm{C} \text { for } \\
24 \mathrm{~h}\end{array}$ & $\begin{array}{l}13.33 \mathrm{hk} \\
\pm 0.58 \\
\end{array}$ & $\begin{array}{l}22.00 \mathrm{~b} \\
\pm 3.80\end{array}$ & $17.67 \mathrm{CD}$ & $\begin{array}{c}19.33 \mathrm{im} \\
\pm 2.20 \\
\end{array}$ & $\begin{array}{c}25.67 \mathrm{de} \\
\pm 1.74 \\
\end{array}$ & $22.50 \mathrm{D}$ & $\begin{array}{l}17.67 \mathrm{de} \\
\pm 1.15 \\
\end{array}$ & $\begin{array}{l}24.33 \mathrm{~b} \\
\pm 3.15 \\
\end{array}$ & $21.00 \mathrm{~B}$ \\
\hline $\begin{array}{l}\text { Water extract at } 50^{\circ} \mathrm{C} \text { for } 20 \\
\text { min }\end{array}$ & $\begin{array}{l}12.67 \mathrm{ik} \\
\pm 1.15 \\
\end{array}$ & $\begin{array}{l}17.33 \mathrm{df} \\
\pm 2.76 \\
\end{array}$ & $15.90 \mathrm{~F}$ & $\begin{array}{l}25.33 \mathrm{de} \\
\pm 4.70\end{array}$ & $\begin{array}{l}30.00 \mathrm{~b} \\
\pm 1.73 \\
\end{array}$ & $27.67 \mathrm{~B}$ & $\begin{array}{l}15.67 \mathrm{eg} \\
\pm 1.16 \\
\end{array}$ & $\begin{array}{l}21.67 \mathrm{c} \\
\pm 2.00\end{array}$ & $18.67 \mathrm{D}$ \\
\hline $\begin{array}{l}\text { Ethanol extract at } 50^{\circ} \mathrm{C} \text { for } 20 \\
\text { min }\end{array}$ & $\begin{array}{l}15.67 \mathrm{fh} \\
\pm 2.40 \\
\end{array}$ & $\begin{array}{l}23.33 \mathrm{~b} \\
\pm 3.51 \\
\end{array}$ & $19.50 \mathrm{BC}$ & $\begin{array}{l}27.0 \mathrm{~cd} \\
\pm 1.15 \\
\end{array}$ & $\begin{array}{l}35.67 \mathrm{a} \\
\pm 2.67 \\
\end{array}$ & $31.33 \mathrm{~A}$ & $\begin{array}{l}16.76 \mathrm{df} \\
\pm 2.15 \\
\end{array}$ & $\begin{array}{l}24.33 \mathrm{~b} \\
\pm 2.31 \\
\end{array}$ & $20.53 \mathrm{BC}$ \\
\hline $\begin{array}{l}\text { Methanol extract at } 50^{\circ} \mathrm{C} \text { for } \\
20 \text { min }\end{array}$ & $\begin{array}{l}14.67 \mathrm{fi} \\
\pm 2.60 \\
\end{array}$ & $\begin{array}{l}28.33 \mathrm{a} \\
\pm 3.00 \\
\end{array}$ & $21.50 \mathrm{~A}$ & $\begin{array}{l}29.67 \mathrm{~b} \\
\pm 3.70\end{array}$ & $\begin{array}{c}34.33 \mathrm{a} \\
\pm 5.8 \\
\end{array}$ & $32.00 \mathrm{~A}$ & $\begin{array}{l}17.33 \mathrm{df} \\
\pm 2.33\end{array}$ & $\begin{array}{r}28.0 \mathrm{a} \\
\pm 3.50 \\
\end{array}$ & $22.67 \mathrm{~A}$ \\
\hline Boiling water for $5 \mathrm{~min}$ & $\begin{array}{c}17.67 \mathrm{de} \\
\pm 3.70 \\
\end{array}$ & $\begin{array}{l}24.00 \mathrm{~b} \\
\pm 2.65 \\
\end{array}$ & $20.83 \mathrm{AB}$ & $\begin{array}{c}20.33 \mathrm{hk} \\
\pm 1.53 \\
\end{array}$ & $\begin{array}{c}23.67 \mathrm{eg} \\
\pm 3.79 \\
\end{array}$ & $22.00 \mathrm{DF}$ & $\begin{array}{c}17.00 \mathrm{df} \\
\pm 1.00 \\
\end{array}$ & $\begin{array}{l}21.33 \mathrm{c} \\
\pm 2.08 \\
\end{array}$ & $19.17 \mathrm{CD}$ \\
\hline Boiling water for10 min & $\begin{array}{l}14.67 \mathrm{fi} \\
\pm 2.90\end{array}$ & $\begin{array}{c}17.67 \mathrm{de} \\
\pm 1.56\end{array}$ & 16.17DE & $\begin{array}{c}19.33 \mathrm{im} \\
\pm 1.73\end{array}$ & $\begin{array}{c}20.33 \mathrm{hk} \\
\pm 3.06\end{array}$ & $19.83 \mathrm{~F}$ & $\begin{array}{l}13.00 \mathrm{hi} \\
\pm 1.53\end{array}$ & $\begin{array}{c}15.67 \mathrm{eg} \\
\pm 2.00\end{array}$ & $14.33 \mathrm{GH}$ \\
\hline Boiling water for $20 \mathrm{~min}$ & $\begin{array}{l}10.67 \mathrm{k} \\
\pm 2.08 \\
\end{array}$ & $\begin{array}{c}13.67 \mathrm{gj} \\
\pm 0.50 \\
\end{array}$ & $12.17 \mathrm{G}$ & $\begin{array}{c}18.03 \mathrm{~km} \\
\pm 4.16 \\
\end{array}$ & $\begin{array}{c}21.33 \mathrm{gi} \\
\pm 4.46 \\
\end{array}$ & $19.67 \mathrm{~F}$ & $\begin{array}{l}11.33 \mathrm{i} \\
\pm 2.10 \\
\end{array}$ & $\begin{array}{c}15.33 \mathrm{fg} \\
\pm 2.08 \\
\end{array}$ & $13.33 \mathrm{H}$ \\
\hline Water Soxhlet extract & $\begin{array}{l}12.33 \mathrm{ik} \\
\pm 1.73 \\
\end{array}$ & $\begin{array}{l}14.00 \mathrm{gj} \\
\pm 1.50 \\
\end{array}$ & $13.17 \mathrm{FG}$ & $\begin{array}{l}15.33 n \\
\pm 5.77\end{array}$ & $\begin{array}{c}17.00 \mathrm{mn} \\
\pm 3.7\end{array}$ & $16.17 \mathrm{G}$ & $\begin{array}{l}11.67 \mathrm{i} \\
\pm 2.53\end{array}$ & $\begin{array}{c}14.00 \mathrm{gh} \\
\pm 0.58\end{array}$ & $12.83 \mathrm{H}$ \\
\hline Ethanol Soxhlet extract & $\begin{array}{c}16.00 \mathrm{eh} \\
\pm 1.80 \\
\end{array}$ & $\begin{array}{c}19.00 \mathrm{~cd} \\
\pm 1.15 \\
\end{array}$ & $17.50 \mathrm{D}$ & $\begin{array}{l}19.67 \mathrm{il} \\
\pm 1.14 \\
\end{array}$ & $\begin{array}{c}24.33 \mathrm{ef} \\
\pm 1.96 \\
\end{array}$ & $22.00 \mathrm{DE}$ & $\begin{array}{c}15.33 \mathrm{fg} \\
\pm 2.00 \\
\end{array}$ & $\begin{array}{l}18.67 \mathrm{~d} \\
\pm 3.50 \\
\end{array}$ & $17.00 \mathrm{EF}$ \\
\hline Methanol Soxhlet extract & $\begin{array}{c}18.33 \mathrm{de} \\
\pm 1.53 \\
\end{array}$ & $\begin{array}{c}21.67 \mathrm{bc} \\
\pm 2.60 \\
\end{array}$ & $20.02 \mathrm{AB}$ & $\begin{array}{c}21.33 \mathrm{gi} \\
\pm 1.53 \\
\end{array}$ & $\begin{array}{c}28.33 \mathrm{bc} \\
\pm 2.08 \\
\end{array}$ & $24.83 \mathrm{C}$ & $\begin{array}{c}17.67 \mathrm{de} \\
\pm 1.50 \\
\end{array}$ & $\begin{array}{c}23.33 \mathrm{bc} \\
\pm 3.87 \\
\end{array}$ & $20.50 \mathrm{BC}$ \\
\hline Pomegranate juice & $\begin{array}{l}13.33 \mathrm{hk} \\
\pm \quad 1.82 \\
\end{array}$ & $\begin{array}{c}16.33 \mathrm{dg} \\
\pm 2.50 \\
\end{array}$ & $13.83 \mathrm{EF}$ & $\begin{array}{c}23.67 \mathrm{eg} \\
\pm 2.08 \\
\end{array}$ & $\begin{array}{c}28.67 \mathrm{bc} \\
\pm 4.8\end{array}$ & $26.17 \mathrm{BC}$ & $\begin{array}{l}12.33 \mathrm{hi} \\
\pm 3.00\end{array}$ & $\begin{array}{l}15.33 \mathrm{fg} \\
\pm 2.31 \\
\end{array}$ & $13.83 \mathrm{H}$ \\
\hline Mean conc. & 14.13B & $20.15 \mathrm{~A}$ & & $21.50 \mathrm{~B}$ & $25.56 \mathrm{~A}$ & & 14.82B & $20.23 \mathrm{~A}$ & \\
\hline
\end{tabular}

$\mathrm{a}, \mathrm{b}, \mathrm{c}, \ldots \ldots \mathrm{n}$ means within column with different letters different significantly $(\mathrm{p} \leq 0.05)$ from each other means followed by the same letter don't differz at 0.05 probability level. 
Table 5. Effect of pomegranate peel extracts and juice on some fungi

\begin{tabular}{|c|c|c|c|c|c|c|}
\hline \multirow[t]{3}{*}{ Treatments } & \multicolumn{3}{|c|}{ Aspergillus niger } & \multicolumn{3}{|l|}{ Candida albicans } \\
\hline & \multicolumn{3}{|c|}{ inhibition zone (mm) } & & & \\
\hline & $20 \mu$ & $40 \mu$ & Mean & $20 \mu$ & $40 \mu$ & Mean \\
\hline Water extract at $25^{\circ} \mathrm{C}$ for $24 \mathrm{~h}$ & $\begin{array}{l}11.0 \mathrm{~b} \\
\pm 1.15\end{array}$ & $\begin{array}{l}21.3 \mathrm{dg} \\
\pm 1.52\end{array}$ & $16.17 \mathrm{C}$ & $25.67 \mathrm{ik} \pm 0.58$ & $\begin{array}{l}30.0 \mathrm{cf} \\
\pm 1.52\end{array}$ & $27.83 \mathrm{D}$ \\
\hline Ethanol extract at $25^{\circ} \mathrm{C}$ for $24 \mathrm{~h}$ & $19.67 \mathrm{fi} \pm 2.08$ & $24 \mathrm{de} \quad \pm 2.3$ & $21.83 \mathrm{~B}$ & $\begin{array}{l}29.0 \mathrm{eh} \\
\pm 5.72\end{array}$ & $\begin{array}{l}33.0 \mathrm{ab} \\
\pm 4.70\end{array}$ & $31.0 \mathrm{BC}$ \\
\hline Methanol extract at $25^{\circ} \mathrm{C}$ for $24 \mathrm{~h}$ & $\begin{array}{l}22.67 \mathrm{df} \\
\pm 0.50\end{array}$ & $\begin{array}{l}31.76 \mathrm{a} \\
\pm 1.90\end{array}$ & $27.17 \mathrm{~A}$ & $29.0 \mathrm{eh} \pm 0.76$ & $\begin{array}{l}33.33 \mathrm{ab} \\
\pm 1.67\end{array}$ & $31.17 \mathrm{~B}$ \\
\hline Water extract at $50^{\circ} \mathrm{C}$ for $20 \mathrm{~min}$ & $18.67 \mathrm{gj} \pm 1.51$ & $\begin{array}{l}23 \mathrm{df} \\
\pm 1.50 \\
\end{array}$ & $20.83 B$ & $\begin{array}{l}26.67 \mathrm{ji} \\
\pm 1.50 \\
\end{array}$ & $\begin{array}{l}\text { 31.33be } \\
\pm 2.72\end{array}$ & $29.00 \mathrm{CD}$ \\
\hline Ethanol extract at $50^{\circ} \mathrm{C}$ for $20 \mathrm{~min}$ & $20.67 \mathrm{eh} \pm 1.15$ & $\begin{array}{l}30.0 \mathrm{ab} \\
\pm 1.15 \\
\end{array}$ & $25.33 \mathrm{~A}$ & $\begin{array}{l}29.33 \mathrm{eh} \\
\pm 2.30 \\
\end{array}$ & $\begin{array}{l}32.33 b c \\
\pm 3.40\end{array}$ & $30.83 \mathrm{BC}$ \\
\hline Methanol extract at $50^{\circ} \mathrm{C}$ for $20 \mathrm{~min}$ & $24.33 \mathrm{~cd} \pm 2.63$ & $\begin{array}{l}26.0 \mathrm{bc} \\
\pm 2.60\end{array}$ & $25.50 \mathrm{~A}$ & $\begin{array}{l}\text { 32.0bd } \\
\pm 1.00\end{array}$ & $\begin{array}{l}35.33 \mathrm{a} \\
\pm 2.95\end{array}$ & $33.67 \mathrm{~A}$ \\
\hline Boiling water for $5 \mathrm{~min}$ & $15.33 \mathrm{jn} \pm 1.15$ & $\begin{array}{l}17.67 \mathrm{hk} \\
\pm 1.52 \\
\end{array}$ & $16.50 \mathrm{C}$ & $\begin{array}{l}23.331 \mathrm{ln} \\
\pm 1.52 \\
\end{array}$ & $\begin{array}{l}26.33 \mathrm{hj} \\
\pm 1.53 \\
\end{array}$ & $24.33 \mathrm{E}$ \\
\hline Boiling water for $10 \mathrm{~min}$ & $13.33 \mathrm{mq} \pm 2.08$ & $\begin{array}{l}15.33 \mathrm{jn} \\
= \pm 1.70\end{array}$ & $14.33 \mathrm{CD}$ & $\begin{array}{l}18.67 \mathrm{op} \\
\pm 1.57\end{array}$ & $\begin{array}{l}21.3310 \\
\pm 2.33\end{array}$ & $20.00 \mathrm{G}$ \\
\hline Boiling water for $20 \mathrm{~min}$ & $10.33 q \pm 0.57$ & $\begin{array}{l}12.33 \mathrm{nq} \\
\pm 1.00\end{array}$ & $11.33 \mathrm{E}$ & $\begin{array}{l}17.33 p \\
\pm 2.3 \\
\end{array}$ & $\begin{array}{l}20.33 \mathrm{no} \\
\pm 3.50 \\
\end{array}$ & $18.83 \mathrm{GH}$ \\
\hline Water Soxhlet extract & $12.0 \mathrm{nq} \pm 0.58$ & $\begin{array}{l}13.33 \mathrm{mq} \\
\pm 2.08\end{array}$ & $12.67 \mathrm{DE}$ & $\begin{array}{l}16.33 \mathrm{pq} \\
\pm 3.20\end{array}$ & $\begin{array}{l}20.67 \mathrm{mo} \\
\pm 1.50\end{array}$ & $18.50 \mathrm{GH}$ \\
\hline Methanol Soxhlet extract & $13.67 \mathrm{nq} \pm 2.08$ & $\begin{array}{l}14.67 \mathrm{ko} \\
\pm 2.80 \\
\end{array}$ & $14.17 \mathrm{CD}$ & $\begin{array}{l}20.67 \mathrm{mo} \\
\pm 2.10 \\
\end{array}$ & $\begin{array}{l}23.67 \mathrm{jl} 1 \\
\pm 2.42 \\
\end{array}$ & $22.17 \mathrm{~F}$ \\
\hline Ethanol Soxhlet extract & $16.0 \mathrm{jm} \pm 1.00$ & $\begin{array}{l}17.0 \text { il } \\
\pm 5.03 \\
\end{array}$ & $16.50 \mathrm{C}$ & $\begin{array}{l}23.33 \mathrm{~km} \\
\pm 0.57 \\
\end{array}$ & $\begin{array}{l}27.67 \mathrm{fi} \\
\pm 3.13 \\
\end{array}$ & $25.50 \mathrm{E}$ \\
\hline pomegranate juice & $11.33 \mathrm{oq} \pm 2.40$ & $\begin{array}{l}14.33 \mathrm{kp} \\
\pm 2.12\end{array}$ & $12.83 \mathrm{DE}$ & $\begin{array}{l}13.67 q \\
\pm 1.80\end{array}$ & $21.3310 \pm 2.60$ & $17.50 \mathrm{H}$ \\
\hline Mean conc. & $16.08 \mathrm{~B}$ & $20.11 \mathrm{~A}$ & & $23.38 \mathrm{~B}$ & $27.44 \mathrm{~A}$ & \\
\hline
\end{tabular}

$\mathrm{a}, \mathrm{b}, \mathrm{c}, \ldots \ldots \ldots \mathrm{.}$ means within column with different letters differ significant $(\mathrm{p} \leq 0.05)$ from each other means followed by the same letter don't differ at 0.05 probability level. 
Table 6. Effect of orally intake pomegranate juice and peel water extract on serum glucose and lipid profile.

\begin{tabular}{|c|c|c|c|c|c|}
\hline Groups & $\begin{array}{l}\text { Blood serum glucose } \\
\mathrm{mg} / \mathrm{dl}\end{array}$ & $\begin{array}{l}\text { Triglyceride } \\
(\mathrm{mg} / \mathrm{dl})\end{array}$ & $\begin{array}{l}\text { Total cholesterol } \\
(\mathrm{mg} / \mathrm{dl})\end{array}$ & $\begin{array}{l}\mathrm{LDL} \\
(\mathrm{mg} / \mathrm{dl})\end{array}$ & $\begin{array}{l}\mathrm{HDL} \\
(\mathrm{mg} / \mathrm{dl})\end{array}$ \\
\hline Control Basal diet & $81.09 \mathrm{ce} \pm 11.00$ & $61.46 \mathrm{df} \pm 4.0$ & $100.30 \mathrm{e} \pm 5.9$ & $39.25 \mathrm{f} \pm 1.60$ & $45.45 \mathrm{bd} \pm 1.12$ \\
\hline $\begin{array}{c}\text { Basal diet }+ \\
\text { Pomegranate juice }\end{array}$ & $58.47 \mathrm{e} \pm 7.38$ & $53.62 \mathrm{eg} \pm 3.63$ & $95.84 \mathrm{f} \pm 4.33$ & $35.02 \mathrm{eg} \pm 2.30$ & $47.13 \mathrm{bd} \pm 1.48$ \\
\hline $\begin{array}{c}\text { Basal diet }+ \\
\text { Pomegranate peel extract }\end{array}$ & $53.80 \mathrm{e} \pm 13.07$ & $49.37 \mathrm{~g} \pm 6.45$ & $87.54 \mathrm{fg} \pm 4.50$ & $32.54 \mathrm{fg} \pm 0.97$ & $49.30 \mathrm{a} \pm 1.62$ \\
\hline Diabetic control group + Basal diet & $420.10 \mathrm{a} \pm 86.32$ & $91.87 \mathrm{~b} \pm 7.69$ & $131.60 \mathrm{~b} \pm 7.55$ & $68.24 \mathrm{c} \pm 1.70$ & $29.03 \mathrm{~g} \pm 0.97$ \\
\hline $\begin{array}{r}\text { Diabetic }+ \text { Basal diet }+ \\
\text { pomegranate juice }\end{array}$ & $123.80 \mathrm{~b} \pm 25.14$ & $63.98 \mathrm{de} \pm 3.28$ & $122.73 c \pm 5.70$ & $49.77 \mathrm{ef} \pm 0.83$ & $45.86 \mathrm{bd} \pm 1.00$ \\
\hline $\begin{array}{c}\text { Diabetic }_{\text {pomegranate }}^{+} \\
\text {peel extract }\end{array}$ & $110.33 b c \pm 10.46$ & $50.46 f g \pm 4.28$ & $108.50 \mathrm{de} \pm 6.80$ & $48.86 \mathrm{eg} \pm 1.09$ & $46.64 \mathrm{bd} \pm 2.60$ \\
\hline $\begin{array}{l}\text { Hypercholesterolemia control group + } \\
\text { Basal diet }\end{array}$ & $102.00 \mathrm{bd} \pm 16.40$ & $121.65 \mathrm{a} \pm 16.67$ & $157.85 a \pm 4.78$ & $109.00 \mathrm{a} \pm 3.40$ & $29.77 \mathrm{~g} \pm 1.90$ \\
\hline $\begin{array}{l}\text { Hypercholesterolemia }+ \text { Basal diet }+ \\
\text { Pomegranate juice }\end{array}$ & $61.91 \mathrm{e} \pm 9.32$ & $76.42 \mathrm{c} \pm 3.21$ & $137.20 \mathrm{~b} \pm 4.95$ & $87.60 \mathrm{~b} \pm 2.50$ & $36.05 \mathrm{eg} \pm 1.51$ \\
\hline $\begin{array}{c}\text { Hypercholesterolemia }+ \text { Basal diet }+ \\
\text { Pomegranate peel extract }\end{array}$ & $60.42 \mathrm{e} \pm 9.90$ & $59.61 \mathrm{eg} \pm 5.40$ & $131.66 \mathrm{~b} \pm 2.48$ & $69.57 \mathrm{c} \pm 1.03$ & $43.43 \mathrm{ce} \pm 1.33$ \\
\hline
\end{tabular}
Pomegranate peel extract

a,b,c,..g means within column with differ letters different significantly ( $\mathrm{p} \leq 0.05$ )from each other means followed by the same letter don't differ at 0.05 probability level. Each value represents the mean of 5 rats \pm S.E. 
Also, data in Table (6) show that administration of pomegranate juice and peel water extract caused significant decrement in triglycerides, total cholesterol and LDL. High density lipoprotein (HDL) showed significant increment in the diabetic group and hypercholesterolemia group administrated with pomegranate water extract comparing with diabetic and hypercholesterolemia control groups.
The obtained results are in agreement with those reported by Radhika et al. (2011) and AbdelRahim et al. (2013) .

Data in Table (7) show the effect of orally intake pomegranate peel water extract and juice on serum bilirubin, protein, albumin, AST, ALT and ALP.

Table 7. Effect of orally intake pomegranate juice and peel water extract on liver functions.

\begin{tabular}{|c|c|c|c|c|c|c|}
\hline Groups & $\begin{array}{l}\text { Total } \\
\text { Bilirubin } \\
(\mathrm{mg} / \mathrm{dl})\end{array}$ & $\begin{array}{l}\text { Total } \\
\text { protein } \\
(\mathrm{g} \backslash \mathrm{l})\end{array}$ & $\begin{array}{l}\text { Albumin } \\
(\mathrm{g} / \mathrm{dl})\end{array}$ & $\begin{array}{l}\text { AST } \\
(\mathrm{U} / \mathrm{L})\end{array}$ & $\begin{array}{l}\text { ALT } \\
(\mathrm{U} / \mathrm{L})\end{array}$ & $\begin{array}{l}\text { ALP } \\
(\mathrm{U} / \mathrm{L})\end{array}$ \\
\hline Control Basal diet & $\begin{array}{r}0.902 b \\
\pm 0.14\end{array}$ & $\begin{array}{r}6.95 \mathrm{~d} \\
\pm 0.91\end{array}$ & $\begin{array}{l}2.78 \mathrm{e} \\
\pm 0.26\end{array}$ & $\begin{array}{l}24.85 f g \\
\pm 2.93\end{array}$ & $\begin{array}{l}34.09 \mathrm{gh} \pm \\
1.19\end{array}$ & $\begin{array}{l}84.06 \mathrm{df} \\
\pm 4.6\end{array}$ \\
\hline Basal diet + & $\begin{array}{l}1.70 \mathrm{ab} \\
+013\end{array}$ & $\begin{array}{l}6.574 d \\
+052\end{array}$ & $2.95 \mathrm{be}$ & $22.10 \mathrm{~g}$ & $31.28 \mathrm{hi}$ & $83.09 \mathrm{df}$ \\
\hline $\begin{array}{c}\text { Pomegranate juice } \\
\text { Basal diet + }\end{array}$ & $\begin{array}{l} \pm 0.13 \\
1.67 \mathrm{ab}\end{array}$ & $\begin{array}{l} \pm 0.52 \\
6.57 \mathrm{~d}\end{array}$ & $\begin{array}{l} \pm 0.42 \\
2.97 \mathrm{de}\end{array}$ & $\begin{array}{l} \pm 1.80 \\
23.54 \mathrm{gf}\end{array}$ & $\begin{array}{l} \pm 2.59 \\
29.97 \mathrm{i}\end{array}$ & $\begin{array}{l} \pm 2.0 \\
77.60 \mathrm{f}\end{array}$ \\
\hline $\begin{array}{l}\text { Pomegranate peel } \\
\text { extract }\end{array}$ & \pm 0.11 & \pm 0.75 & \pm 0.57 & \pm 1.24 & \pm 3.00 & \pm 3.62 \\
\hline $\begin{array}{l}\text { Diabetic control group }+ \text { Basal } \\
\text { diet }\end{array}$ & $\begin{array}{l}2.10 \mathrm{a} \\
\pm 0.08\end{array}$ & $\begin{array}{l}6.93 \mathrm{~d} \\
\pm 0.91\end{array}$ & $\begin{array}{l}3.51 \mathrm{be} \\
\pm 0.41\end{array}$ & $\begin{array}{r}43.53 \mathrm{~b} \\
\pm 4.93\end{array}$ & $\begin{array}{l}66.83 b \\
\pm 3.19\end{array}$ & $\begin{array}{r}98.69 \mathrm{c} \\
\pm 5.67\end{array}$ \\
\hline $\begin{array}{l}\text { Diabetic }+ \text { Basal diet }+ \\
\text { pomegranate juice }\end{array}$ & $\begin{array}{r}1.64 \mathrm{ab} \\
\pm 0.08\end{array}$ & $\begin{array}{l}6.82 \mathrm{~d} \\
\pm 0.27\end{array}$ & $\begin{array}{l}3.05 \mathrm{ce} \\
\pm 0.43\end{array}$ & $\begin{array}{r}37.64 \mathrm{~d} \\
\pm 3.13\end{array}$ & $\begin{array}{r}54.15 \mathrm{e} \\
\pm 1.52\end{array}$ & $\begin{array}{l}87.43 \mathrm{de} \\
\pm 4.25\end{array}$ \\
\hline $\begin{array}{c}\text { Diabetic }+ \\
\text { pomegranate } \\
\text { peel extract }\end{array}$ & $\begin{array}{l}1.716 \mathrm{ab} \\
\pm 0.08\end{array}$ & $\begin{array}{l}6.59 \mathrm{~d} \\
\pm 0.75\end{array}$ & $\begin{array}{l}3.66 \mathrm{bd} \\
\pm 0.65\end{array}$ & $\begin{array}{r}32.76 \mathrm{e} \\
\pm 1.34\end{array}$ & $\begin{array}{l}48.26 f \\
\pm 1.60\end{array}$ & $\begin{array}{l}\text { 79.97ef } \\
\pm 2.95\end{array}$ \\
\hline $\begin{array}{l}\text { Hypercholesterolemia control } \\
\text { group }+\quad \text { Basal diet }\end{array}$ & $\begin{array}{l}2.53 \mathrm{a} \\
\pm 0.23\end{array}$ & $\begin{array}{l}9.60 \mathrm{a} \\
\pm 0.42\end{array}$ & $\begin{array}{l}4.53 \mathrm{a} \\
\pm 1.11\end{array}$ & $\begin{array}{l}56.26 \mathrm{a} \\
\pm 1.45\end{array}$ & $\begin{array}{l}77.26 \mathrm{a} \\
\pm 4.90\end{array}$ & $\begin{array}{c}147.30 \mathrm{a} \\
\pm 8.45\end{array}$ \\
\hline $\begin{array}{c}\text { Hypercholesterolemia + Basal } \\
\text { diet }+ \\
\text { Pomegranate juice }\end{array}$ & $\begin{array}{l}1.70 \mathrm{ab} \\
\pm 0.27\end{array}$ & $\begin{array}{l}7.02 \mathrm{~cd} \\
\pm 0.57\end{array}$ & $\begin{array}{l}3.457 \mathrm{be} \\
\pm 0.70\end{array}$ & $\begin{array}{l}37.12 \mathrm{~d} \\
\pm 1.77\end{array}$ & $\begin{array}{l}59.85 \mathrm{~cd} \\
\pm 2.50\end{array}$ & $\begin{array}{c}114.60 \mathrm{~b} \\
\pm 3.43\end{array}$ \\
\hline $\begin{array}{c}\text { Hypercholesterolemia + Basal } \\
\text { diet }+ \\
\text { Pomegranate peel extract }\end{array}$ & $\begin{array}{l}1.91 \mathrm{ab} \\
\pm 0.06\end{array}$ & $\begin{array}{l}7.75 b c \\
\pm 0.83\end{array}$ & $\begin{array}{r}3.45 \mathrm{be} \\
\pm 0.33\end{array}$ & $\begin{array}{l}35.29 \mathrm{de} \\
\pm 1.32\end{array}$ & $\begin{array}{c}57.17 \mathrm{de} \\
\pm 1.10\end{array}$ & $\begin{array}{c}112.50 \mathrm{~b} \\
\pm 2.60\end{array}$ \\
\hline
\end{tabular}

$a, b, c, . . f$ means within column with differ letters different significantly $(\mathrm{p} \leq 0.05)$ from each other means followed by the same letter don't differ at 0.05 probability level.

Each value represent the mean of 5 rats \pm S.E.

Diabetic groups had non significant change in total bilrubin, total protein and albumin and showed significant decrement in AST, ALT and ALP comparing with diabetic control group.

Hypercholesterolemia groups showed significant reduction in total protein, albumin, AST, ALT and ALP comparing with hypercholesterolemia control group.

The obtained results are in agreement with those reported by Osman et al. (2012) and Bhandary et al. (2013).

\section{Kidney functions}

Data concerning the effect of orally intake pomegranate juice and peel water extract on kidney functions are shown in Table (8).

Diabetic and hypercholesterolemia groups had significant increment in urea, uric acid and creatinine comparing to control group fed on basal diet.
Administration of pomegranate juice and peel water extract showed significant decrement in these parameters comparing with diabetic and hypercholesterolemia control groups .

The obtained results are in agreement with those reported by (Abdel-Rahim et al 2013) and Bhandary et al. (2013).

Effect of pomegranate juice and peel water extract on heamatological Parameters:

Data concerning the effect of orally intake pomegranate juice and peel water extract on the hematological parameters are shown in Table (9). There was significant increment in WBC in diabetic group. While, hypercholesterolemia group showed significant increment in $\mathrm{WBC}$ and $\mathrm{RBC}$ in the group administrated with pomegranate juice.

The obtained results are in agreement with Bhandary et al. (2013). 
Table 8. Effect of orally intake pomegranate juice and peel water extract on kidney functions.

\begin{tabular}{|c|c|c|c|}
\hline Groups & $\begin{array}{l}\text { Urea } \\
\mathrm{mg} / \mathrm{dl}\end{array}$ & $\begin{array}{l}\text { Uric acid } \\
\mathrm{mg} / \mathrm{dl}\end{array}$ & $\begin{array}{c}\text { Creatinine } \\
\mathrm{mg} / \mathrm{dl}\end{array}$ \\
\hline Control Basal diet & $50.97 f g \pm 3.75$ & $2.81 \mathrm{de} \pm 0.15$ & $0.28 \mathrm{~cd} \pm 0.10$ \\
\hline $\begin{array}{c}\text { Basal diet }+ \\
\text { Pomegranate juice }\end{array}$ & $39.82 \mathrm{~h} \pm 1.40$ & $2.35 \mathrm{ef} \pm 0.34$ & 0.15 hi \pm 0.07 \\
\hline $\begin{array}{c}\text { Basal diet }+ \\
\text { Pomegranate peel extract }\end{array}$ & $40.18 \mathrm{~h} \pm 2.80$ & $3.20 \mathrm{~d} \pm 0.12$ & $0.13 \mathrm{i} \pm 0.04$ \\
\hline Diabetic control group + Basal diet & $80.61 \mathrm{a} \pm 6.11$ & $4.64 a b \pm 0.39$ & $0.37 b \pm 0.12$ \\
\hline $\begin{array}{r}\text { Diabetic }+ \text { Basal diet }+ \\
\text { pomegranate juice }\end{array}$ & $54.83 \mathrm{ef} \pm 2.80$ & $3.914 c \pm 0.18$ & $0.24 \mathrm{df} \pm 0.11$ \\
\hline $\begin{array}{c}\text { Diabetic }+ \\
\text { pomegranate } \\
\text { peel extract } \\
\text { Basal diet }+ \\
\end{array}$ & $58.6 \mathrm{de} \pm 1.90$ & $3.82 c \pm 0.29$ & $0.252 \mathrm{df} \pm 0.03$ \\
\hline $\begin{array}{l}\text { Hypercholesterolemia control group + } \\
\text { Basal diet }\end{array}$ & $83.63 \mathrm{a} \pm 5.50$ & $5.05 a \pm 0.23$ & $0.528 \mathrm{a} \pm 0.18$ \\
\hline $\begin{array}{l}\text { Hypercholesterolemia + Basal diet }+ \\
\text { Pomegranate juice }\end{array}$ & $58.5 \mathrm{de} \pm 0.97$ & $4.00 \mathrm{c} \pm 0.16$ & $0.318 b c \pm 0.11$ \\
\hline $\begin{array}{c}\text { Hypercholesterolemia + Basal diet + } \\
\text { Pomegranate peel extract }\end{array}$ & $46.23 \mathrm{gh} \pm 1.00$ & $4.28 b c \pm 0.30$ & $0.27 \mathrm{ce} \pm 0.04$ \\
\hline
\end{tabular}

Table 9. Effect of orally intake of pomegranate juice and peel water extract on hematological Parameters.

\begin{tabular}{|c|c|c|c|}
\hline Groups & $\begin{array}{c}\mathrm{RBC} \\
\left(\mathrm{X} 10^{6} / \mu \mathrm{l}\right)\end{array}$ & $\begin{array}{c}\text { WBC } \\
\left(\mathrm{X} 10^{3} / \mu \mathrm{l}\right)\end{array}$ & $\begin{array}{l}\mathrm{Hb} \\
(\mathrm{g} / \mathrm{dl})\end{array}$ \\
\hline Control Basal diet & $\begin{array}{l}6.70 \mathrm{ab} \\
\pm 0.31\end{array}$ & $\begin{array}{l}15.78 \mathrm{eg} \\
\pm 2.3\end{array}$ & $\begin{array}{l}14.34 \mathrm{ac} \\
\pm 0.61\end{array}$ \\
\hline $\begin{array}{c}\text { Basal diet }+ \\
\text { Pomegranate juice }\end{array}$ & $\begin{array}{l}6.92 \mathrm{ab} \\
\pm 0.23 \\
\end{array}$ & $\begin{array}{l}19.90 \mathrm{~b} \\
\pm 2.07 \\
\end{array}$ & $\begin{array}{l}14.00 \mathrm{~b} \\
\pm 0.7\end{array}$ \\
\hline $\begin{array}{c}\text { Basal diet }+ \\
\text { Pomegranate peel extract }\end{array}$ & $\begin{array}{l}7.02 \mathrm{ab} \\
\pm 0.24\end{array}$ & $\begin{array}{l}19.04 \mathrm{~b} \\
\pm 3.11\end{array}$ & $\begin{array}{l}14.6 \mathrm{ab} \\
\pm 0.45\end{array}$ \\
\hline Diabetic control group + Basal diet & $\begin{array}{l}6.54 \mathrm{ac} \\
\pm 0.39 \\
\end{array}$ & $\begin{array}{l}14.6 \mathrm{~g} \\
\pm 2.4 \\
\end{array}$ & $\begin{array}{l}13.34 \mathrm{df} \\
\pm 1.36 \\
\end{array}$ \\
\hline $\begin{array}{l}\text { Diabetic }+ \text { Basal diet }+ \\
\text { pomegranate juice }\end{array}$ & $\begin{array}{l}6.77 \mathrm{ab} \\
\pm 0.61\end{array}$ & $\begin{array}{l}16.06 \mathrm{ef} \\
\pm 2.54 \\
\end{array}$ & $\begin{array}{l}13.54 \mathrm{cf} \\
\pm 1.44 \\
\end{array}$ \\
\hline 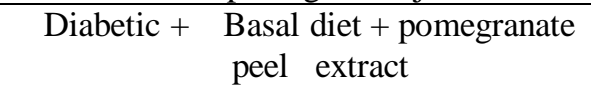 & $\begin{array}{l}6.75 \mathrm{ab} \\
\pm 0.08\end{array}$ & $\begin{array}{l}21.36 \mathrm{a} \\
\pm 3.35\end{array}$ & $\begin{array}{l}13.46 \mathrm{cf} \\
\pm 0.45\end{array}$ \\
\hline $\begin{array}{l}\text { Hypercholesterolemia control group + } \\
\text { Basal diet }\end{array}$ & $\begin{array}{r}5.76 c \\
\pm 0.55\end{array}$ & $\begin{array}{l}17.60 \mathrm{~cd} \\
\pm 1.64\end{array}$ & $\begin{array}{l}12.86 \mathrm{ef} \\
\pm 0.06\end{array}$ \\
\hline $\begin{array}{c}\text { Hypercholesterolemia + Basal diet + } \\
\text { Pomegranate juice }\end{array}$ & $\begin{array}{l}6.95 \mathrm{ab} \\
\pm 0.31\end{array}$ & $\begin{array}{l}18.98 b \\
\pm 2.11\end{array}$ & $\begin{array}{l}13.46 \mathrm{cf} \\
\pm 0.45\end{array}$ \\
\hline $\begin{array}{c}\text { Hypercholesterolemia }+ \text { Basal diet }+ \\
\text { Pomegranate peel extract }\end{array}$ & $\begin{array}{l}6.71 \mathrm{ac} \\
\pm 0.16\end{array}$ & $\begin{array}{l}18.71 \mathrm{bc} \\
\pm 2.00\end{array}$ & $\begin{array}{l}13.66 \mathrm{be} \\
\pm 0.37\end{array}$ \\
\hline
\end{tabular}

$a, b, c, . . f$ means within column with different letters differ significant $(\mathrm{p} \leq 0.05)$ from each other means followed by the same letter don't differ at 0.05 probability level.

Each value represent the mean of 5 rats \pm S.E.

\section{References}

A.O.A.C. (2005).Official Methods of Analysis of the Association of Official Agricultural Chemists, $17^{\text {th }}$ ed, published by A.O.A.C.

Abdel Moneim, A. E., Dkhil, M. A. and AlQuraishy, S.(2011). Studies on the effect of pomegranate (Punica granatum) juice and peel on liver and kidney

in adult male rats. Journal of Medicinal Plants

Research. 5(20):5083-5088.

Abdel-Rahim, E.A.; El-Beltagi H.S. and Romela

R.M. (2013). White Bean seeds and Pomegranate peel and fruit seeds as 
hypercholesterolemic and hypolipidemic agents in albino rats. Grasas Y Aceites, 64 (1):50-58.

AlFadel, F., Al Laham,S., and Alkhatib,R.,(2014). The Anti-Bacterial activity of various parts of Punica granatum on antibiotic resistance Escherichia coil International Journal of Pharmacognosy and Phytochemical Research 6(1): $\quad$ 79-85

Al-Rawahi, A. S.; Rahman, M. S.; Guizani, N. and Essa, M, M. (2013). Chemical Composition, Water Sorption Isotherm, and Phenolic Contents in Fresh and Dried Pomegranate Peels. Drying Technology, 31: 257-263.

Allain, C.C.; Poon, L.S.; Chan, C.S. and Richmond, W. (1974). Enzymatic determination of total serum cholesterol. Clin. Chem., 20: 470-475.

Al-Zoreky NS.( 2009) . Antimicrobial activity of pomegranate (Punica granatum L.) fruit peels. Int J Food Microbiol, 134:244-248 .

Bagri, P.; Ali, M.; Aeri, V.; Bhowmik, M. and Sultana, S. (2009). Antidiabetic effect of Punica granatum flowers: effect of hyperlipidemia, pancreatic cells lipid peroxidation and antioxidant enzymes in experimental diabetes. Food Chem. Toxicol. 47(1):50-54.

Bhandary, B. S.K.; Sharmila, Kumari, K.P N. S. and Vadisha S. (2013). Acute and subacute toxicity study of the ethanol extracts of punica granatum (Linn). whole fruit and seeds and synthetic ellagic acid in swiss albino mice. Asian J. Pharm. Clin. Res. 6(4): 192-198.

Buko V, Luklvskaya O, Nkitin V, Tarasov Y, Zavodink L, Borodassky A,

Cioren T, Shetein B, Tanz B, Mudermann KJ (1996). Hepatic and pancreatic effects of polyenoyl phatidyl choline in rats with alloxan induce diabetes. Cell Biochem. Furnet. 14(2):137.

Çam, M. and Hişıl, Y. (2010). Pressurised water extraction of polyphenols from pomegranate peels. Food Chem. 123(3):878-885.

Çam, M. ,Hışıll, Y and Durmaz, G. (2009). Classification of eight pomegranate juices based on antioxidant capacity measured by four methods. Food Chem. 112(3):721-726.

Cheung, L.M.; Cheung, P.C.K. and Ooi, V.C.E. (2000). Antioxidant activity and total phenolics of edible mushroom extracts. Food Chemistry 81:249-255.

Dahham, S.S.; Ali, M.N.; Tabassum, H. and Khan, M. (2010). Studies on Antibacterial and Antifungal Activity of Pomegranate (Punica granatum L.). American-Eurasian J. Agric. \& Environ. Sci., 9 (3): 273-281.

Djeridane, A.; Yousfi, M.; Nadjemi, B.; Boutassouna, D.; Stocker, P. and Vidal, N.
(2006). Antioxidant activity of some Algerian medicinal plants extracts containing phenolic compounds. Food Chem. 97(4):654-660.

Dubois, M.; Smith, F.; Gilles, K.A.; Hammilton, J.K. and Robers, P.A. (1956): Colorimetric method to determination of sugars and related substances. Anal. Chem. 28 (3): 350-356.

Elfalleh, W.; Nasri, N.; Marzougui, N.; Thabti, I.; M'rabet, A.; Yahya, Y.; Lachiheb, B.; Guasmi, F. and Ferchichi, A. (2009). Physico-chemical properties and DPPH-ABTS scavenging activity of some local pomegranate (Punica granatum) ecotypes. Int. J. Food Sci. Nutr. 60(2):197-210.

Elfalleh, W.; Tlili, N.; Nasri, N.; Yahia, Y.; Hannachi, H.; Chaira, N.; Ying, M. and Ferchichi, A. (2011). Antioxidant Capacities of Phenolic Compounds and Tocopherols from Tunisian Pomegranate (Punica granatum) Fruits. J. Food Sci. 76:707-713.

Fawole, O. A, Makunga, N,P and Opara. U. L (2013). Antibacterial, antioxidant and tyrosinase-inhibition fruit peel methanolic extract. BMC Complementary and Alternative Medicine. 12: 200-211.

Fossati, P. and Principe, L. (1982). Enzymatic colorimetric method to determination triglycerides. Clin. Chem., 28: 2077.

Hadrich, F.; Cher, S.; Gargouri, Y.T. and Adel, S. (2014). Antioxidant and lipase inhibitory activities and essential oil composition of pomegranate peel extracts. J. Oleo. Sci. 63(5):515-25.

Hajoori, M., Naik, M., Naik, K. and Desai. S. (2014). Evaluation of antimicrobial activity of punica granatum peel extracts using different solvent sestem. International Journal of Pharmacologycal. 4, 26-31.

Hohnov, B.; Štavikov,L. and Karasek, P. (2008). Determination of anthocyanins in red Grape Skin by Pressurised Fluid Extraction and HPLC. Czech J. Food Sci. 26: S39-S42.

Iddamaldeniya, S.S., Thaberw,M.I., Wickramasingghel, S.M.D., Ratnatunge, N. N. and Thammitiyagodage, M.G., (2006). A long-term investigation of the antihepatocarcinogenic potential of an indigenous medicine comprised of niglla sativa, Hemidesmus indicine and Smilax glabra. J. of Carcinogenesis 5:11-24.

Jin, D. and Russell, J.M. (2010). Plant Phenolics: Extraction, Analysis and Their Antioxidant and Anticancer Properties. Molecules; 15:73137352.

Khan, J.A. and Hanee, S. (2011). Antibacterial properties of punica granatum peels. International Journal of Applied Bacteriology and Pharmaceutical Technology 2(3): 23-27.

Madrigal-Carballo, S. , Rodriguez, G. Krueger, C. Dre- her, M., and Reed, J. (2009). 
"Pomegranate (Punica granatum) Supplements: Authenticity, Antioxidant and Polyphenols Com- position". Journal of Functional Foods 1(3): 324-329.

Moure, A.; Franco, D.; Sineiro, J.; Domı́nguez, H.; Nûň ez, M.J.; Lema, J.M. (2000). Evaluation of extracts from Gevuinaavellana hulls as antioxidants. Journal of Agricultural and Food Chemistry 48: 3890-3897.

Noda, Y.; Kaneyuki, T.; Mori, A. and Packer, L. (2002). Antioxidant activities of pomegranate fruit extract and its anthocyanidins: delphinidin, cyanidin, and pelargonidin. J. Agric. Food Chem. 50(1):166-171.

Okonogi, S.; Duangrat, C.; Anuchpreeda, S.; Tachakittirungrod, S. and Chowwanapoonpohn, S. (2007). Comparison of antioxidant capacities and cytotoxicities of certain fruit peels. Food Chem. 103(3):839-846.

Orak, H.H.; Demirci, A.Ş. and Gümüş, T. (2011) - Antibacterial and antifungal activity of pomegranate (Punica granatum cv.) peel. Electronic Journal of Environmental Agricultural and Food Chemistry 10(3): 19581969.

Orak, H.H.; Yagar, H. and Isbilir, S.S. (2012). Comparison of antioxidant activities of juice, peel, and seed of pomegranate (Punica granatum L.) and inter-relationships with total phenolic, Tannin, anthocyanin, and flavonoid contents. Food Science and Biotechnology 21(2): 373-387.

Osman, H.F.; Eshak, M.G.; El-Sherbiny, E.M. and Bayoumi, M.M. (2012). Biochemical and Genetical Evaluation of Pomegranate Impact on Diabetes Mellitus Induced by Alloxan in Female Rats. Life Science Journal 9(3): 15431553.

Perez, C., and Anesini, C., (1994). In vitro antibacterial activity of Argentine folk medicinal plants against Salmonella typhi.J Ethnopharmacol, 44:41-46.

Radhika, S.; Smila, K.H. and Muthezhilan, R. (2011). Antidiabetic and hypolipidemic Activity of Punica granatum Linn on Alloxan Induced Rats. World Journal of Medical Sciences 6 (4): 178-182.

Ramadan, Afaf- haniem , El-badrawey, S. , Abd el-ghany, M. , and Nagib,R.M. (2010) Utilization of hydro-alcoholic extracts for peel and rind and juice of pomegranate as natural antioxidants in cotton seed oil. The 5thArab and 2nd International Annual Scientific Conference

Reeves, P.G; Nilsen,F.H. and Fahey, G.C.(1993): AIN-93purified diets for laboratory rodents: Final report of the American Institute of Nutrition ad hoc writing committee on the reformulation of the AIN76Arodent diet. J.Nut., 123, 1939-1951.
Rowayshed, G.;Salama, A.; Abul-Fadl, M.;AkilaHamza, S. and Emad, A. M. (2013). Nutritional and Chemical Evaluation for Pomegranate (Punica granatum L.) Fruit Peel and Seeds Powders By Products. Middle East Journal of Applied Sciences, 3(4): 169-179.

SAS.,(1996) SAS procedure Guide.(Version 6.12 Ed). SAS Insitute Inc., Cary, NC,USA.

Shaokat, S.S., Hameed , H. A. and Mohammad, H. J. (2007). Anti-fungal activity of punica granatum peels powder and extracts from pathogenic samples. Iraqi J.Pharm.Sci., 16 (2):12-20.

Tietz, N.W,(1976a). Fundamentals of Clinical Chemistery co.,Philadelphia.p.243.

Tietz, N.W,(1976b). Fundamentals of Clinical Chemistery W.B.Saunders co.,Philadelphia.p.999-1002.

Tietz., N.W. (1986). Textbook of clinical chemistry. WBsaunders, Philadelphia, pp1271-1281.

Tietz, N.W. (1990). Clinical guide to laboratory tests. $2^{\text {nd }}$ ED. Philadelphia: WB Saunders.566.

TM, R.; Rababah, B.F.; Ereifej, A. and Yang, W.K. (2010). Optimization of extraction conditions of total phenolics, antioxidant activities, and anthocyanin of oregano, thyme, terebinth, and pomegranate. J Food Sci. 75(7): C626-632.

Trinder, P. (1969). Determination of Glucose in blood using glucose-oxidase with an alternative oxygen acceptor. Ann. Clin. Biochem. 6: 24-27.

Vassault, A.; Grafmeyer, D.; Naudin, C.; Dumont, G.; Bailly, M. and Henny J. (1986). Protocole de validation de techniques. Ann. Biol. Clin. 44: 686-745.

Walters, M.I. and Gerarde, H.W. (1970). An ultramicromethod for the determination of conjugated and total bilirubin in serum or plasma. Microchemical Journal 15(2): 231-243.

Wang, Z .; Pan, Z .; Mal, H. and Atungulu , G.G. (2011). Extract of phenolics from pomegranate peels. The Open Food Science Journal 5: 17-25.

Wissam, Z.; Ghada, B.; Wassim, A. and Warid, K. (2012). Effective extraction of polyphenols and proanthocyanidins from pomegranate's peel. Int. J. Pharm. Sci. 4(3): 675-682.

Young, D.S.; Thomas, D.W.; Friedman, R.B. and Pestaner, L.C. (1972). Effects of drugs on clinical laboratory tests. Clinical Chemistry 18(1) 1041-1303.

Young, D.S.; Pestaner, L.C. and Gibberman, V. (1975). Effect of drugs on clinical laboratory tests. Clinical Chemistry, 21:1D-432D. 


\section{الملخص}

تهدف هذه الدر اسة إلي در اسة أفضل طريقه لاستخلاص البولي فينول و التانينات و الانثوسيانين و الفلافونويدات ومضادات الأكسدة من قثور الرمان و قد تم استخدام الماءو الميثانول والايثانول علي درجات حرارة 25 25 لمده 24ساعة و50م لمده 20 دقيقه وكذلك الاستخلاص بجهاز

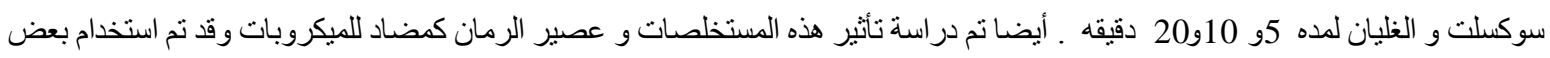
الميكروبات الموجبة لجر ام مثل

( Staphylococcus aureus, Listeria monocytogenese, Bacillus megaterium and Bacillus cereus) والسالبة لجرام مثل (Escherichia coli, Klebsiella pneumonia and Salmonella typi) و الفطريات ثثل (Aspergillus niger and Candida albicans ) كما تم دراسة تأثبر عصير الرمان والمستخلص المائي للقتور علي الفئران المصابة بارتفاع سكر الدم و الفئران التي تعاني من ارتفاع نسه الكوليستيرول . أوضحت النتائج أن المستخلص المائي علي درجه حرارة 50م اعلى اعلي كفاءه في استخلاص البولي فينول و التانينات و الانثوسيانين و

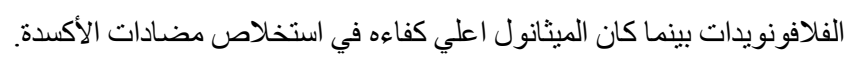

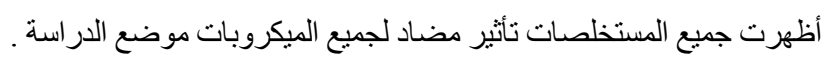
حدث انخفاض في سكر الدم والجلسريدات الثناثثة و الكوليستيرول منخفض الكثافة و اليورياو حمض اليوريك و الكرياتينين بينما حدث ارتفاع في الكوليستيرول عالي الكثافة في الفئران المصابة بارتفاع سكر الدم و الفئران التي تعاني من ارتفاع نسبه الكوليستيرول. أيضا حدث زيادة في عدد كرات الدم البيضاء في الفئران المصابة بارتفاع سكر الدم. 